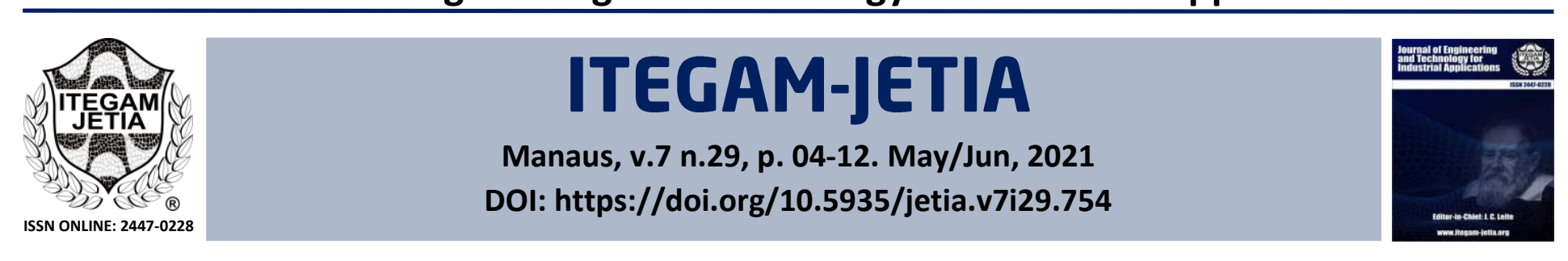

\title{
THE INFLUENCE OF PERFORMANCE EXPECTANCY ON E- PROCUREMENT ADOPTION MODEL IN DEVELOPING COUNTRIES: TANZANIANS PERCEPTION
}

\author{
Deus Nichodemus Shatta*1 and France Shayo ${ }^{2}$ \\ ${ }^{1}$ Department of Business and Entrepreneurship Studies, National Institute of Transport, Dar Es Salaam Tanzania. \\ ${ }^{2}$ Department of Marketing and Entrepreneurship, The Open University of Tanzania, Dar Es Salaam Tanzania.
}

${ }^{1}$ http://orcid.org/0000-0003-1852-6070 (1), ${ }^{2}$ http://orcid.org/0000-0002-3585-292X (i)

Email:*deusshatta@gmail.com, france.shayo@out.ac.tz

\begin{tabular}{|c|c|}
\hline ARTICLE INFO & ABSTRACT \\
\hline $\begin{array}{l}\text { Keywords: } \\
\text { Performance Expectancy, } \\
\text { E-Procurement, } \\
\text { Adoption. }\end{array}$ & $\begin{array}{l}\text { used. Questionnaire and documentary review were used for data collection. Partial Least } \\
\text { Squares Structural Equation Modeling with the help of SmartPLS } 3 \text { software was used to } \\
\text { analyze the collected data. The findings reveal that performance expectancy has direct } \\
\text { influence on e-procurement adoption model. Likewise, performance expectancy has indirect } \\
\text { influence on e-procurement adoption model through relative advantage and attitude. Basing } \\
\text { on these findings, it is concluded that performance expectancy has both direct and indirect } \\
\text { influences on e-procurement adoption model. Therefore, it is recommended that the } \\
\text { Government of Tanzania and other Governments based in developing countries to pay } \\
\text { attention to the performance expectancy on the way to e-procurement adoption systems. }\end{array}$ \\
\hline
\end{tabular}

Copyright (C2016 by authors and Galileo Institute of Technology and Education of the Amazon (ITEGAM). This work is licensed under the Creative Commons Attribution International License (CC BY 4.0).

\section{INTRODUCTION}

\section{I.1 OVERVIEW AND PROBLEM SETTING}

Behavioural intention to use technology is said to be influenced by performance expectancy because it provides benefits to consumers in performing certain activities [1]. However, many studies concerning e-procurement adoption systems have not taken into consideration the performance expectancy as a critical success factor which influences new technology adoption [2-7]. The study by [4] aimed at establishing the factors that influence eprocurement adoption technology in the organization. The findings of this study revealed that e-procurement adoption is influenced by three critical success factors namely internal needs, improved customers relationship and reduction of labour costs. In this study by [4] was recommended that allocation of financial resources, top management support and end-user buy-in can influence eprocurement adoption in any organization. The study by [5] used a cross-sectional research design to establish the factors that influence e-procurement adoption system. A questionnaire was used to collect data from 46 respondents. The collected data were analyzed by using descriptive statistics with the help of IBM SPSS statistics 21 . The findings of this study revealed the following factors which influence e-procurement adoption; employees and management commitment to success of adoption, reliability of information technology and supplier's performance and monitoring the performance of e-procurement system. Based on these findings, this study recommended to the organization to address the factors which were identified towards success of eprocurement adoption. [6] conducted a study to examine the role of e-procurement strategy on the performance of an organization. A cross-sectional research design and descriptive statistics analysis with the help of IBM SPSS statistics 21 were adopted. In addition, inferential statistics with the help of multiple regression and correlation analysis was used to analyze the collected data. The customer service level. The findings revealed that the performance 
of the organization is affected significantly by the service level strategy, procurement cost reduction strategy, inventory optimization strategy and buyer/supplier collaboration strategy, audit and compliance strategy. The study by [6] recommended that the organization needs a good e-procurement system to use in order to reduce the effort and time required for procurement of goods, works and services. The new procurement system was anticipated to eliminate the traditional paper chain from ordering to payment during procurement process. The study by [8] investigated the factors influencing e-procurement adoption. Questionnaire survey was used to collect data from 213 organizations. Descriptive statistics was used to analyze data. The findings revealed that the eliminating geographical barriers, benefits of e-procurement, effective communication among buyer and suppler were most important factors influencing e-procurement adoption. In connection to that, [9] carried out the study whose aim was to understand advantages of e-procurement. A questionnaire was used to collect data from 155 public officials already were using eprocurement and data were processed using IBM SPSS statistics 21 software. The findings revealed that e-procurement adoption results into reduction of corruption, improves monitoring and accountability [9].

Furthermore, [10] aimed to understand the concept of eprocurement, its evolution and adoption in the market economy as well as higher education. The findings revealed that successful implementation of e-procurement would require the following critical success factors: top management support; user acceptance of e-procurement systems; employees and management commitment to success of adoption; reliability of information technology and supplier performance; monitoring the performance of e-procurement systems; Other critical success factors identified were: training of staff in procurement practices; risk perception and continuous measurement of the key benefits, best practices and actual selection of the system [10].

Studies by [8,9] and [10] would have been more interesting if the authors had explained the indirect influences of performance expectancy towards e-procurement adoption. The study by [11] aimed at investigating the level of e-Perolehan system success and the factors that contribute to this success, as perceived by the Government users. The structural equation modeling was used to analyze the data. System compatibility, users' attitude and mimetic pressures were found to be the main significant critical success factors of the e-Perolehan system. The study by [12] examined the factors influencing e-procurement adoption in an organization. Simple random sampling technique was used to sample 97 participants. A questionnaire was used for data collection and the collected data were analyzed by using descriptive statistics. The findings revealed that training of both end users and procurement staff was an important factor in e-procurement adoption. It was recommended that management of financial institutions need to train both end users and procurement staff in order to keep the dynamism of e-procurement [12]. However, some few studies regarding information technology adoption models hypothesized performance expectancy to effect new technology adoption [13], [7], [14]. For example, [7] examined factors influencing adoption of mobile payment services. The study by [7] used survey method to collect data and the collected data were analyzed by using Partial Least Squares Structural Equation Modeling (PLS-SEM). The findings revealed that the consumer' behavioural intention to use mobile payment services is influenced significantly by perceived trust, social influence and effort expectancy. However, performance expectancy and facilitating condition were found to influence insignificantly the consumer' behavioural intention to use mobile payment services [7]. Likewise, the study by [13] revealed that the performance expectancy had insignificant influence towards green e-business adoption. Although the studies by [7] and [13] considered the performance expectancy as an important factor in new technology adoption but both of them did not base on e-procurement adoption. This study was carried out to fill this gap by examining the influence of performance expectancy on e-procurement adoption model in developing countries, Tanzania in particular. In addition to that the Government of Tanzania has been undertaking reforms in the public procurement process with the aim of supporting e-procurement system which is more efficient and transparent in terms of its performance [15]. However, it was noted that regardless of the benefits and the efficient of procurement performance associated with adoption of e-procurement system, 326 (30.9 per cent) of the trained suppliers for piloting Tanzania National electronic Procurement System (TANePS) adoption in the country were reluctant to register in the system $[16,17]$. This situation may disturb the expected benefits and efficient procurement performance of the system.

\section{I.2 OBJECTIVE OF THE STUDY}

The objective of this study was to examine the influence of performance expectancy on e-procurement adoption through relative advantage and attitude as mediator constructs.

\section{I.3 THEORICAL FRAMEWORK}

In reviewing the theoretical literature, it was noted that at this time, researchers combine UTAUT or TOE model with external theories or models or other variables in order to address weaknesses of the theory or model [13], [7], [18]. It has been argued that it is essential to use at least two theories to attain a better understanding of multidimensional new information technology adoption due to the limitations that one theory or model may have [18]. Currently, there exists no collectively accepted theory to explain new technologies adoption and this situation has left researchers in a "theoretical confusion" because scholars have been developing their own theories or extending the existing ones to cater for their research problems [13], [7], [19-22]. For example, the study by [13] developed a model by using all constructs from the original UTAUT, however, one construct was added to furnish the research problem. Likewise, the study by [13] developed a model by using constructs from UTAUT, TOE and Institutional Theory to outfit for research problem.

\section{I.3.1 Theoretical Gap}

The existing theory adopted in the current study (UTAUT) and the model employed (TOE) are clarifying inadequately the combined perspectives (individual' and organizational' perspectives). The current study has developed an integrative model comprehensively explains the combined perspectives by using direct and indirect relationships of the constructs from TOE model and UTAUT of which the original UTAUT and TOE are not explaining clearly. The constructs relative advantage and attitude from TOE model and the construct performance expectancy from UTAUT were integrated and thought to influence directly and indirectly the Tanzania National e-Procurement System (TANePS) adoption. The direct and indirect relationships of these constructs are not comprehended clearly in the original and modified TOE models and UTAUTs. Prior studies with regard to new technology adoption have not applied the complete UTAUT model as found in origin and most of these studies employed only a subset of the model and that moderators were typically dropped or were replaced 
by other moderators [21], [1], [13], [7], [22]. Figure 1 and 2 presents modified UTAUTs of the new technology acceptance and use with an indication for the role of attitude and new moderator which was not suggested by the origin UTAUT.

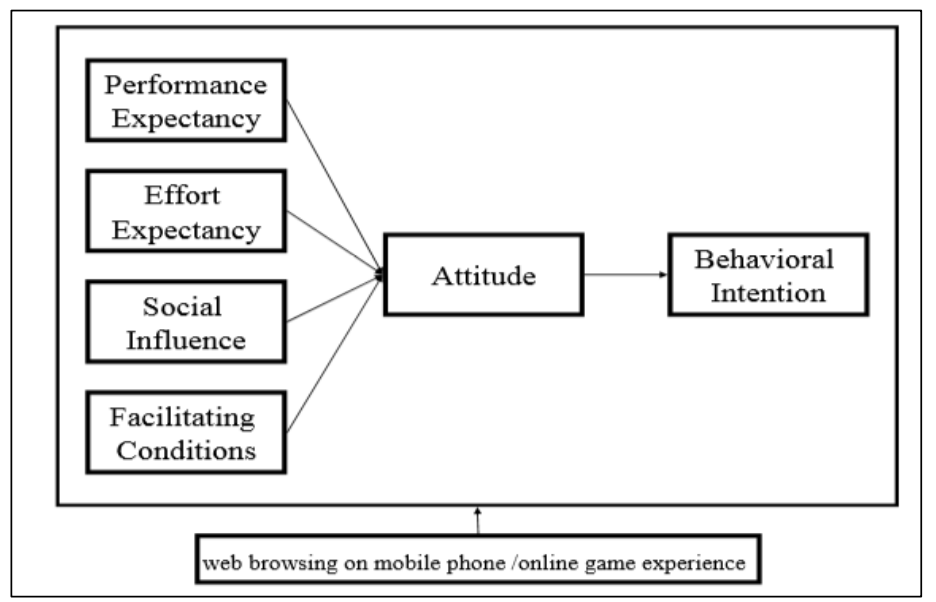

Figure 1: Modified UTAUT. Source: [21].

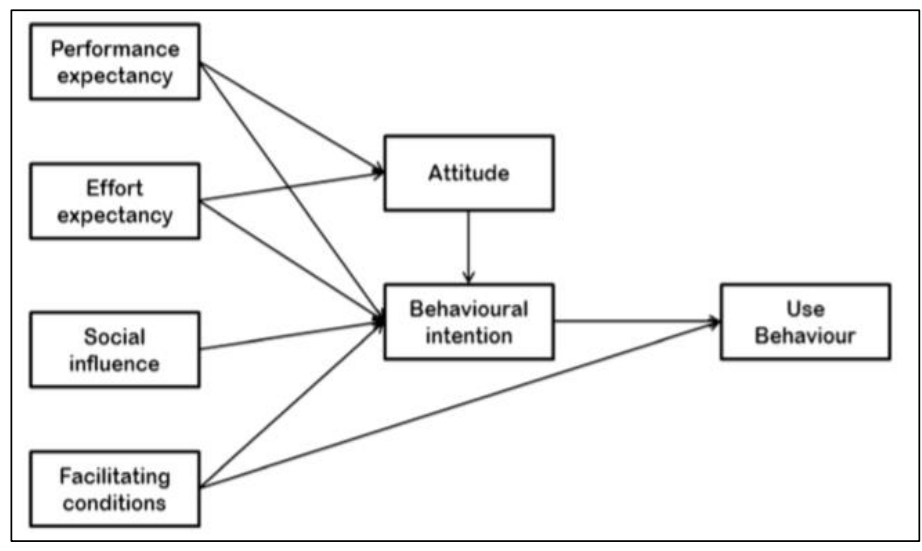

Figure 2: Modified UTAUT.
Source: [22].

Previous studies have also not applied all constructs from TOE model as found in [23]. Most prior studies had been employing only some of the constructs from each element of TOE model towards new technologies adoption [11], [24-27]. For example, the study by [11] adopted the TOE model to examine the level of e-Perolehan system achievement and the influences that subsidize to this achievement, as professed by the Government employers but the study included only attitude of users, learning of organization, expectation of suppliers, compatibility of the system and imitative pressure. The study by [25] also adopted the TOE model to explore the influence of these factors on the innovation decision of firms in the context of a developing country. Figure 3 and 4 presents modified models by [25] and by [26] which ignored some constructs from the original TOE model.

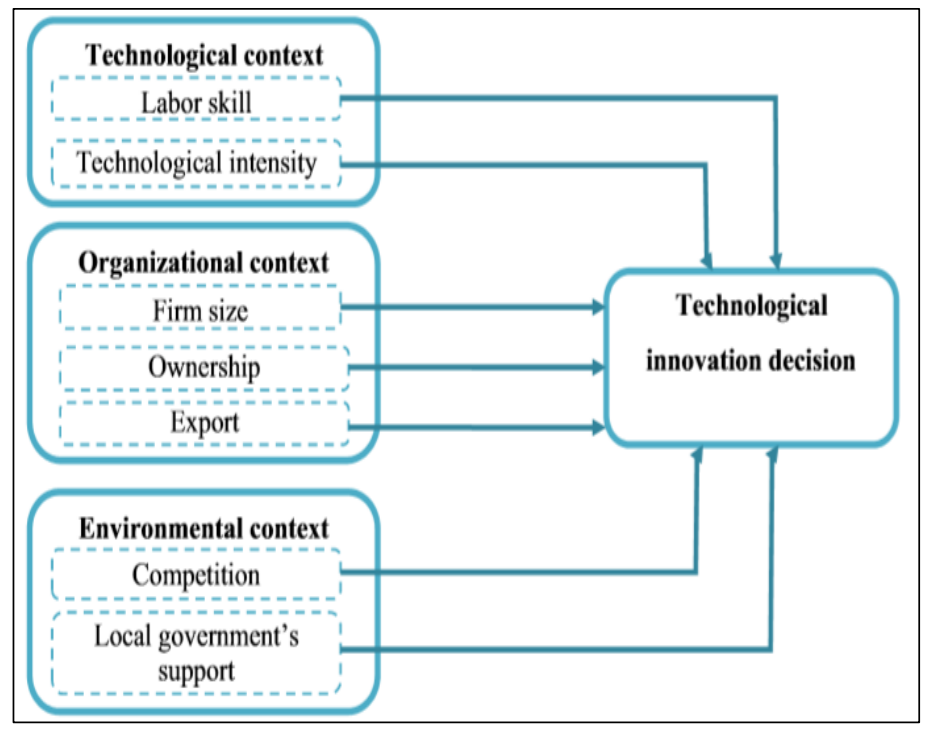

Figure 3: Modified TOE Model. Source: [25].

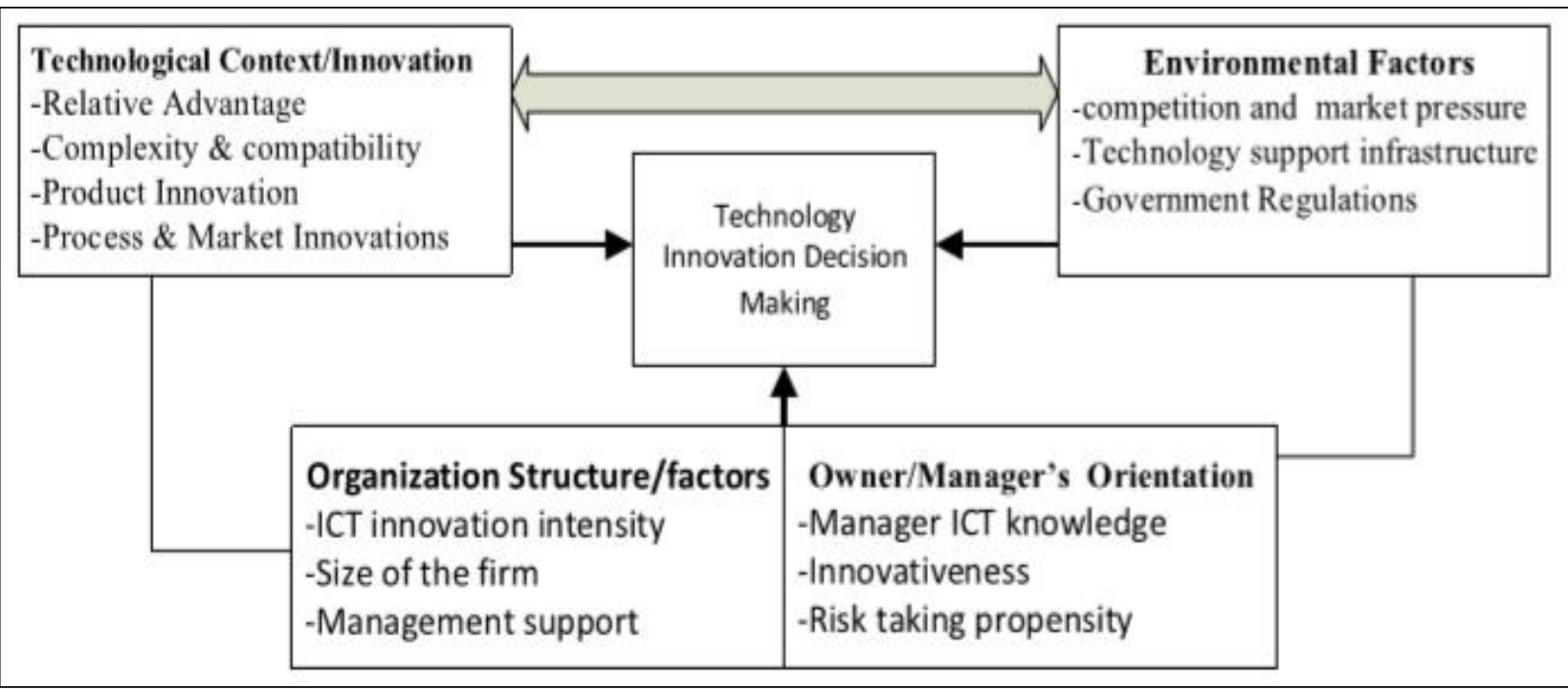

Figure 4: Modified TOE Model.

Source: [26].

A possible reason why prior studies may not have utilized all constructs from the origin UTAUT and TOE model is because some of the constructs might not be useful in their research problems towards new technologies adoption and use context.
Basing on this fact, the current study has adopted TOE model and UTAUT in order to suit its research problem and objectives with regard to TANePS adoption [13], [18], [7], [28], [14], [18], [29]. 


\section{I.4 MODEL CONSTRUCTS AND HYPOTHESES}

This study explains three endogenous constructs and one exogenous construct. Endogenous constructs involve relative advantage, attitude and TANePS adoption. The exogenous construct is performance expectancy.

\section{I.4.1 Performance Expectancy (PE)}

[1] defined performance expectancy as a degree to which using technology will provide direct and indirect benefits to consumers in performing certain activities, and is theorized to influence behavioural intention to use technology. On the other hand, the origin UTAUT theory by [19] suggests that performance expectancy is thought to influence the new technology adoption. This argument of theory was supported by [24] who asserted that the easier it is to use a technology, the greater the expected benefits from the technology with regard to performance enhancement. The underlying principle under performance expectancy is that individuals make decisions rationally and systematically on the basis of the system available.

In this study, performance expectancy was postulated to positively, directly and indirectly effect TANePS adoption basing on the fact from the theory and the underlying principle.

$H_{1}$ : Performance Expectancy has positive and direct effect on TANePS adoption.

$\mathrm{H}_{2}$ : Performance Expectancy has positive and indirect effect on TANePS adoption through attitude.

$\mathrm{H}_{3}$ : Performance Expectancy has positive and indirect effect on TANePS adoption through relative advantage.

\section{I.4.2 Relative Advantage (RA)}

Relative advantage is the extent to which the innovation is viewed by users to be better than the existing idea; i.e., perceived cost and benefits [30]. However, perceived benefits include 'direct and indirect benefits' like reduction in transaction errors and transaction costs, improved data accuracy and faster tendering process [31]. In this study, relative advantage was postulated to positively effect TANePS adoption.

$\mathrm{H}_{4}$ : Relative advantage has positive and direct effect on TANePS adoption.

\section{I.4.3 Attitude (AT)}

User's attitude in this context of study means having positive or negative mindset of buyers or suppliers towards eprocurement adoption in public sector [11] which includes like or dislike of the system; willing to learn or not willing to learn about the application of the system; committed or not committed to use the system in public procurement process; frequently interact or not frequently interact with the system in public procurement process. In this study attitude was postulated to positively effect TANePS adoption in public sector. adoption.

$H_{5}$ : Attitude has positive and direct effect on TANePS

\section{I.4.4 Conceptual Model of the Study}

For the purpose of validation of these assertions a number of direct and indirect effects of the constructs on TANePS adoption were conceptualized as depicted in Figure 5.

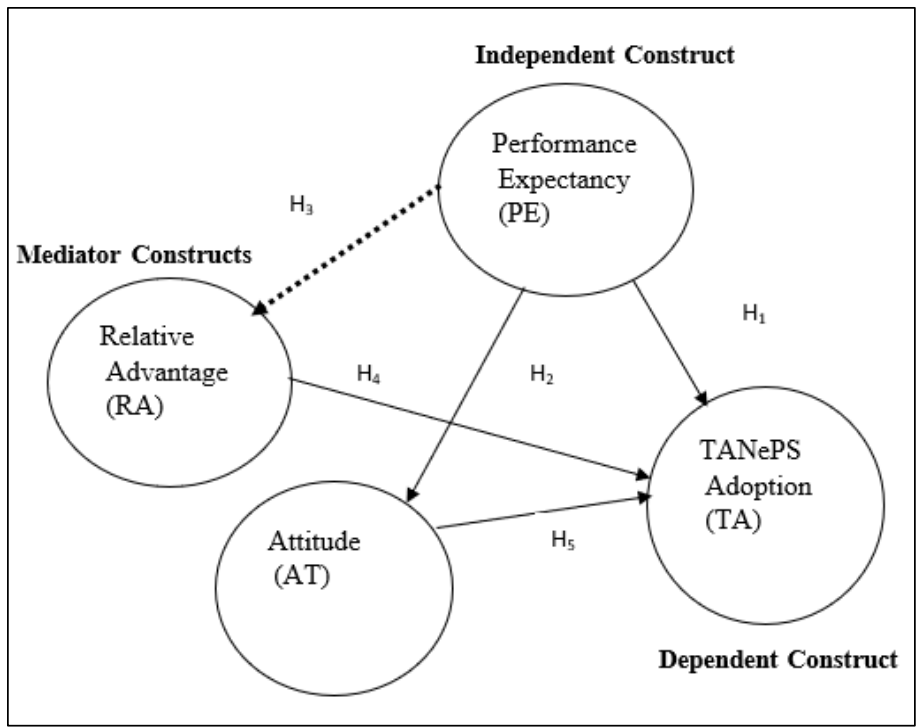

Figure 5: Conceptual Model of the Study. Source: Authors, (2021).

Key: Relationships Exist in Literature. Theoretical Gap (Does not Exist in Literature).

\section{METHODS}

Positivism philosophy and cross-sectional survey research design were adopted. In addition, stratified sampling technique was adopted and a sample of 157 respondents was used. Questionnaire and documentary review were used for data collection. Based on research model of this study, the rule of thumb proposed by [32, 33] for applying PLS-SEM and SmartPLS 3 software in data analysis was used to justify the minimum number of sample size required. Forty (40) respondents were regarded to be the minimum number of sample size for testing the hypotheses of research model. This is due to the fact that the exogenous construct (performance expectancy) had a maximum of four indicators. Per rule of thumb proposed by [33], four indicators, times ten was equivalent to forty (40). Therefore, a sample of 157 respondents was sufficient for data analysis in this study.

The respondents' general information was operationally measured by using non-parametric measurements for sex and education level. The responses were based on nominal scale attitude questions. However, respondents' age and experience were operationally measured by using parametric measurements of which complete age and experience were filled in the questionnaire. The dependent variable, mediator variables and the independent variable were operationally measured by using non parametric measurements. TANePS adoption had four indicators (service performance, efficiency, transparency and information quality), performance expectancy had four indicators (simplification of procurement process, simplification of payment process, removal of chances of corruption, reduction of procurement cycle time), relative advantage had four indicators (reduction in transaction errors, transaction costs, improved data accuracy, faster tendering process) and attitude had four indicators (acceptance of the system, intention to learn, plan to use, intention to take advantage). The responses were based on a five Likert scale (ordinal) questions.

Questionnaires with closed ended questions were assigned numbers to enable the process of quantitative data analysis to be more accurate and simpler. The collected quantitative data were analyzed by using descriptive statistics with the help of IBM SPSS 
Statistics software 21 Version and by using Partial Least Squares Structural Equation Modeling (PLS-SEM) with the help of SmartPLS 3 software. Based on the complexity of the research model and the sample size of this study, PLS-SEM was the best non-parametric multivariate method that could allow data analysis by incorporating both (direct and indirect) relationships between the constructs and between the indicators and unobservable variables of the research model.

\section{FINDINGS}

\section{III.1 EDUCATION LEVEL OF RESPONDENTS}

The findings concerning education level against type of respondents revealed that majority of the respondents from procuring entities had higher levels of education than suppliers.
Procurement experts from procuring entities who responded in this study were as follows: eight per cent were holding diploma in procurement, 50 per cent were holding bachelor degree in procurement and 42 per cent were holding post graduate degrees related to procurement. For suppliers who responded in this study the finding revealed that 66.7 per cent were holding diplomas in different fields, certificates in various fields, certificates of secondary and primary education, 26.3 per cent were holding bachelor degree in different fields and 7.0 per cent of the respondents were holding post graduate degrees in different fields. These findings implied that the information and data provided by the respondents for this study were actual and comprehensive. Table 1 shows the education level of respondents against type of respondents.

Table 1: Education Level of the Respondents.

\begin{tabular}{|c|c|c|c|c|}
\hline \multirow{5}{*}{ Education Level of Respondents } & \multicolumn{2}{|c|}{ Type of Respondent } & \multirow{2}{*}{ Total } \\
\cline { 3 - 5 } & & Procurement Expert & Suppliers & \\
\hline & Primary Educ. & 0 & 4 & 4 \\
\cline { 2 - 5 } & Secondary Educ. & 0 & 15 & 15 \\
\cline { 2 - 5 } & Certificate Level & 0 & 5 & 5 \\
\cline { 2 - 5 } & Diploma Level & 8 & 14 & 22 \\
\cline { 2 - 5 } & Bachelor Degree & 50 & 15 & 65 \\
\cline { 2 - 5 } & Master's Degree & 41 & 0 & 4 \\
\cline { 2 - 5 } & PhD Degree & 1 & $\mathbf{5 7}$ & $\mathbf{1 5 7}$ \\
\hline
\end{tabular}

Source: Authors, (2021).

\section{III.2 MEAN AND STANDARD DEVIATION OF THE RESPONDENT'S EXPERIENCE}

Apart from education of the respondents, the study also revealed that about 10 years was a mean of the respondents with regard to their experience which had good implications for the data and information collected for this study. However, there was significant dispersion of experience in years from one respondent to another due to the fact that the standard deviation from the mean was about 8 years close to its mean. Figure 6 shows the mean and standard deviation of the respondents' experience.

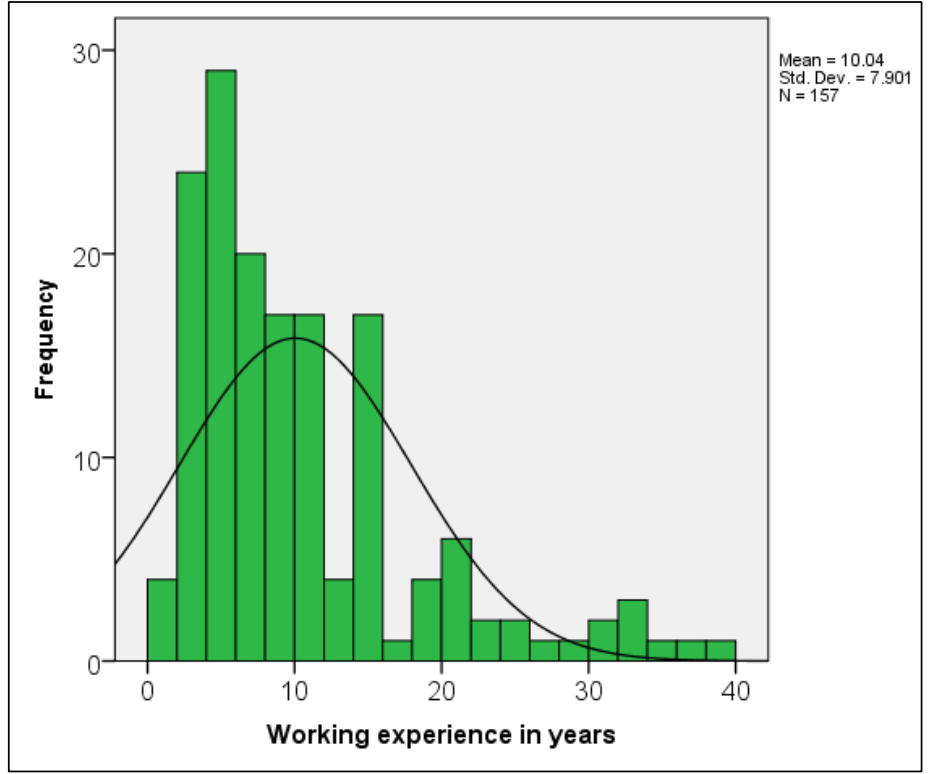

Figure 6: The Mean and Standard Deviation of the Respondents' Experience.

Source: Authors, (2021).

\section{III.3 MEAN AND STANDARD DEVIATION OF THE RESPONDENTS' AGE}

The study also revealed that about 40 years was the mean age of the respondents. In addition, there was insignificant dispersion of years from one respondent to another due to the fact that the standard deviation from the mean age was only about 10 years. This finding implied that the ages of the respondents were not scattered and therefore, the information and data provided for this study was very comprehensive and genuine. Figure 7 shows the mean and standard deviation of the respondents' ages of the study.

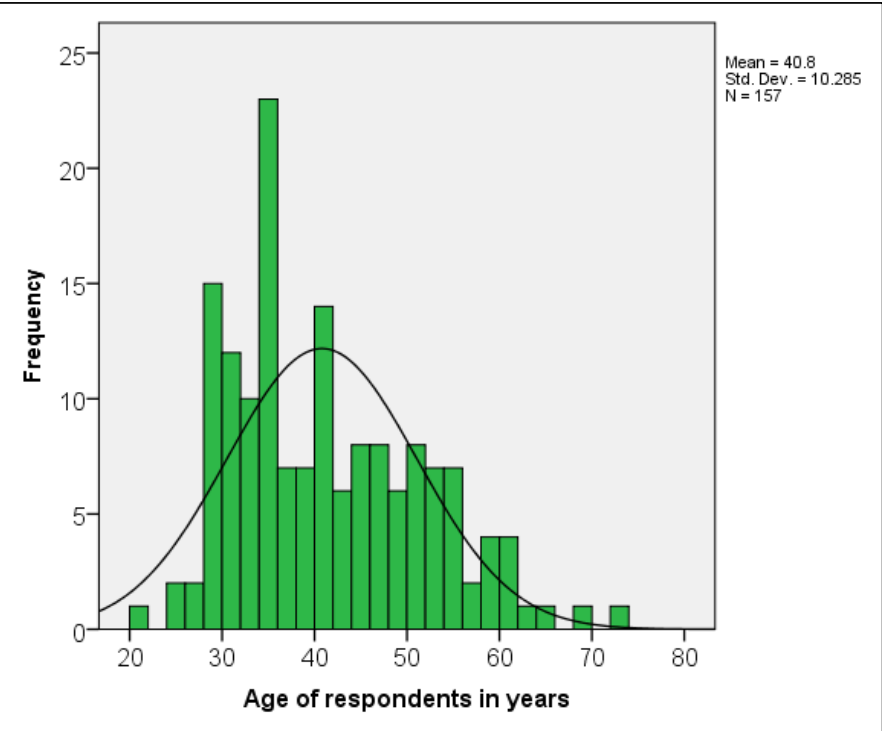

Figure 7: Mean and Standard Deviation of the Respondents' Ages.

Source: Authors, (2021). 


\section{III.4 RELEVANCE OF PATH COEFFICIENTS AND STATISTICAL SIGNIFICANCE OF THE HYPOTHESIZED RELATIONSHIPS}

After performing PLS algorithm, the report from SmartPLS 3 for relevance of the path coefficients of the research model showed that the path coefficients of the hypothesized relationships of performance expectancy and TANePS adoption were positive which meant that an increase in one standard deviation of the performance expectancy results into increase of the rate of TANePS adoption. In addition, the direct and indirect relationships of the performance expectancy were supported. Figure 8 and 9 show the relevance of path coefficients and statistical significance of the hypothesized relationships.

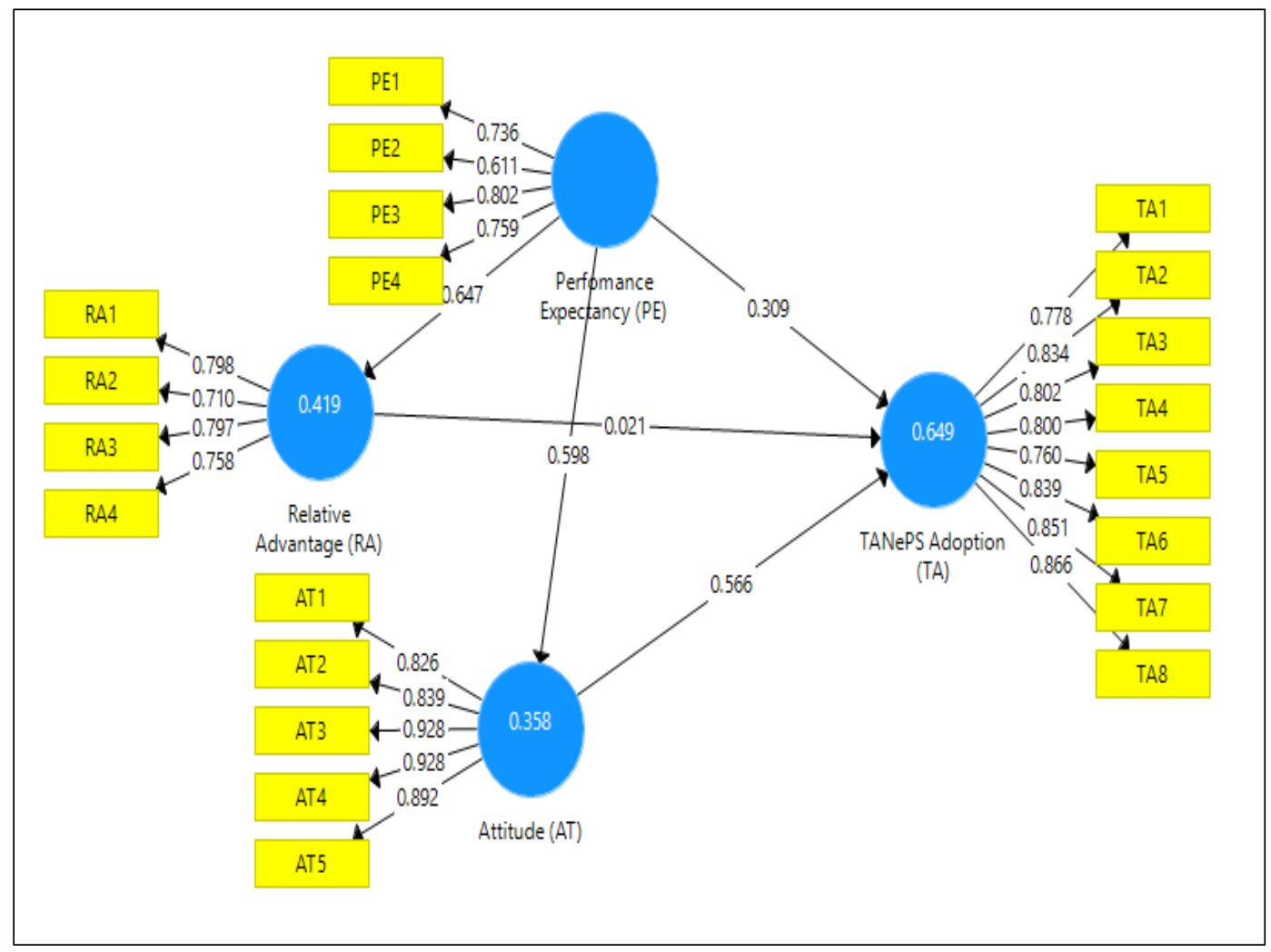

Figure 8: Relevance of the Path Coefficients.

Source: Authors, (2021).

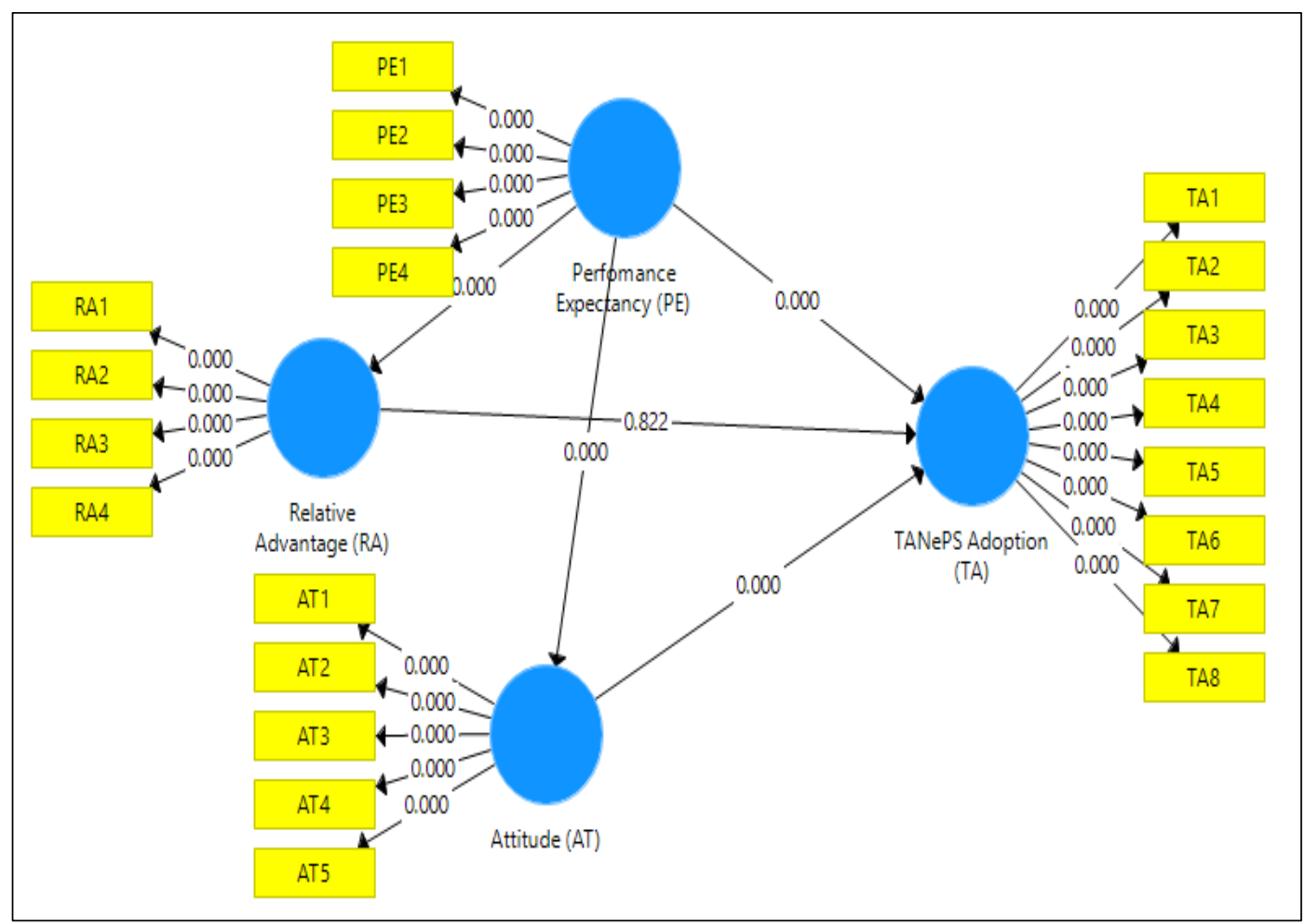

Figure 9: Statistical Significance of the Hypotheses. Source: Authors, (2021). 
This study adopted mediators (relative advantage and attitude) that accounted for part of the relationships between predictor (performance expectancy) and the outcome (TANePS adoption) and the steps for testing mediating effects were adopted as described by [33]. The direct effect does not have to be significant for full mediation, if the indirect effect is insignificant then no mediation, the situation of partial mediation occurs when both the direct and indirect effects are significant while full mediation occurs when the direct effect is not significant and the indirect effect is significant. The hypotheses tested from the conceptual model based on direct and indirect effects of performance expectancy towards TANePS adoption and are summarized in Table 2.

Table 2: Findings of Direct and Indirect Hypotheses.

\begin{tabular}{|c|l|c|c|c|}
\hline Hypothesis & \multicolumn{1}{|c|}{ Path } & Influence & P-value & Remark \\
\hline $\mathrm{H}_{1 \mathrm{a}}$ & $\begin{array}{l}\text { PE->TA } \\
\mathrm{H}_{1}\end{array}$ & Direct & 0.000 & Supported \\
\hline $\mathrm{H}_{1 \mathrm{~b}}$ & $\begin{array}{l}\text { PE->RA->TA } \\
\mathrm{H}_{3}, \mathrm{H}_{4}\end{array}$ & Indirect & 0.000 & Supported \\
\hline $\mathrm{H}_{1 \mathrm{c}}$ & $\begin{array}{l}\mathrm{PE}->\mathrm{AT}->\mathrm{TA} \\
\mathrm{H}_{2}, \mathrm{H}_{5}\end{array}$ & Indirect & 0.000 & Supported \\
\hline
\end{tabular}

Source: Authors, (2021).

\section{DISCUSSION OF FINDINGS}

\section{IV.1 THE INFLUENCE OF PERFORMANCE EXPECTANCY}

In this study, performance expectancy was proposed to positively, directly and indirectly influence TANePS adoption. The results of both direct and indirect influences showed positive path coefficients which implied that an increase in one standard deviation of the performance expectancy converted into an increment of the rate of TANePS adoption and both relationships were found statistically significant ( $p$-values were $<0.05$ ). These results implied that the relationships exist in real life. Likewise, these results are parallel to the previous studies of [21] and [22] which indicated that the direct and indirect influences of performance expectancy to new technologies adoption through attitude was statistically significant. However, the findings of the current study contrast from some prior studies. For example, [7] revealed that performance expectancy (PE) was found statistically insignificant towards Behavioural Intention to utilize Mobile. The study by [7] reasoned that performance expectancy being immaterial could propose that buyers don't just depend on performance expectancy so as to embrace and utilize portable payment directions. However, this factor additionally doesn't influence buyers' choices according to the study by [7]. In addition, the study by [13] characterized performance expectancy as the degree to which an individual accepts that utilizing a specific framework will upgrade their activity execution. A similar report set that the higher the performance expectancy among the small and medium travel industry undertakings, the higher the effect on expectation to embrace and utilize green e-business. These results indicated the immaterial influence of performance expectancy on green e-business reception because of the way that the p-value was more prominent than 0.05 , while the path coefficient was under 0.2 , suggesting that, it was less significant for conversation and accordingly, it was disposed of.

\section{CONCLUSION}

\section{V.1 THEORETICAL CONTRIBUTION}

Despite the fact that these results of the current study are consistent with the origin UTAUT but the origin UTAUT considered only individual perspectives as criticized by [22]. In this way, the current study has added new information with respect to the impact of performance expectancy on new innovation (TANePS) adoption because it has included two points of view; public and private divisions of which the current theories and prior studies are lighting up incapably. The determinant of performance expectancy from UTAUT to influence positively, directly, and indirectly the reception of new innovation (TANePS) in the public to cooperating with relative advantage and attitude from TOE is a substantial miss in the existing theories and models. In addition, this study argues that performance expectancy is one of the powerful constructs which TOE model did not consider in technological factors as one of the determinants for adopting new technologies. This argument is valid and has been justified by this study. Taking into account the relationships between performance expectancy and relative advantage and attitude for TANePS adoption, the findings revealed that performance expectancy had both direct and indirect influences towards TANePS adoption. Since performance expectancy influences new technology adoption both directly and indirectly, then, this study suggests that it should be added in technological factors list in TOE model.

\section{V.2 EMPIRICAL CONTRIBUTION}

Taking into consideration the focus of the previous empirical studies conducted in developing countries and the focus of this study, it is therefore concluded that the empirical gap which was existing has been filled. This is due to the fact that, this study has included both the perception of buyers (procurement experts from procuring entities) and suppliers a substance that the existing empirical literature was explaining insufficiently. Furthermore, the integrated conceptual model with constructs influencing directly and indirectly the adoption of new technology (TANePS) for buyers' and suppliers' perspectives has been well comprehended in this study of which the existing empirical studies are explaining the indirect relationships inadequately. The indirect relationships between performance expectancy from UTAUT and relative advantage and attitude from TOE model have been sufficiently comprehended in this study, a substance that the existing empirical literature was missing. In this study, positivism philosophy and deductive-forecasting approach were adopted. In connection to that, PLS SEM with the help of SmartPLS 3 was adopted in data analysis of which the existing empirical literature related to eprocurement adoption have used these approach and method insufficiently. 


\section{V.3 PRACTICAL IMPLICATION}

The results from the tested hypotheses in the conceptual model has practical implications in terms of applicability of TANePS in the public sector. With reference to the relationship between relative advantage and TANePS adoption. For relative advantage being statistically insignificant in direct relationship with TANePS adoption could suggest that buyers and suppliers during TANePS adoption, expansion and reform do not only rely on relative advantage of the system in order to adopt and use the new system. Hence, relative advantage of the system does not influence buyers' and suppliers' decisions to adopt and use TANePS. However, performance expectancy and attitude influence buyers' and suppliers' decisions to adopt and use TANePS because the direct and indirect relationships with TANePS adoption were found statistically significant.

\section{V.4 RECOMMENDATION}

Policymakers need to restructure the ICT and public procurement policies to be in line with e-procurement adoption using the final model of this study. The final integrated model of this study has implications in public procurement policy with regard to the factors influencing TANePS adoption, expansion and reform of the system in the public sector. This study has identified performance expectancy as a predictor factor while relative advantage and attitude are mediators towards TANePS adoption as an outcome. The public procurement policy makers should take into consideration these factors during expansion and reform of TANePS.

\section{LIMITATIONS OF THE STUDY AND AREAS FOR FUTURE RESEARCH}

This study was limited to three constructs which explained only $64.9 \%$ of the variance in users' intention to use TANePS which implies more constructs are required to be included. It is therefore recommended that further research may increase the number of constructs to improve the variance in users' intention to use TANePS. Additionally, in this study, attention has been paid to the application of reflective model with constructs inducing the indicators. It is therefore recommended that further research would be necessary to apply formative model with specified constructs which are induced by the indicators and have received considerable attention in the recent past.

\section{AUTHOR'S CONTRIBUTION}

Conceptualization: Deus Nichodemus Shatta.

Methodology: Deus Nichodemus Shatta.

Investigation: Deus Nichodemus Shatta.

Discussion of results: Deus Nichodemus Shatta.

Writing - Original Draft: Deus Nichodemus Shatta.

Writing - Review and Editing: Deus Nichodemus Shatta.

Resources: Deus Nichodemus Shatta.

Supervision: France Shayo.

Approval of the final text: France Shayo.

\section{ACKNOWLEDGEMENT}

The authors acknowledge the Tanzania Commission for Science and Technology (COSTECH) for its facilitation and coordination of the workshop on scientific paper writing which was held at Bagamoyo for the purpose of promoting research development activities in Tanzania.

\section{REFERENCES}

[1] V. Venkatesh, J. Y. L., \& Xu, X. Thong. "Consumer Acceptance and Use of Information Technology: Extending the Unified Theory" MIS Quarterly, vol. 36, 1, pp. $157-178,2012$

[2] J. Iles. "How is e-procurement related to the success of U.S. cities' sustainable purchasing policies?" Arizona State University, ASU School of Sustainability, 2017.

[3] F. B. Latif. "The Adoption of Electronic Procurement in Turkey" Advances in Economics and Business, vol. 2,2, 85-91, 2014.

[4] L. M. Mgidlana. "Factors affecting the adoption of e-procurement technologies from the supplier perspective" (Master's Research Project) Gordon Institute of Business Science, University of Pretoria, 2013.

[5] J. M. Mose, J. M. Njihia, \& P. O. Magutu. "The critical success factors and challenges in e-procurement adoption among large scale manufacturing firms in Nairobi, Kenya" European Scientific Journal, vol. 9, 13, pp.1857- 7431, 2013.

[6] N. I. Shale. "Role of e-procurement strategy on the performance of state corporations in Kenya" (PhD Thesis) School of Entrepreneurship and Procurement Management in the College of Human Resource Development, Jomo Kenyatta University of Agriculture and Technology, 2014.

[7] E. A. Taluka. "Understanding factors influencing consumer behavioral intention to use mobile payment services in rural Tanzania: A Case of Pwani Region" (Master's Dissertation) University of Dar es Salaam, 2016.

[8] E. O., Ibem, E.B., Aduwo, P., Tunji-Olayeni, E. K. Ayo-Vaughan, \& O. U. Uwakonye. Factors influencing e-procurement adoption in the Nigerian building industry. Journal of Construction Economics and Building, 16 (4), 54-67, 2016.

[9] D. Malekia. E-Procurement as anti-corruption tool in public procurement in Tanzania. European Journal of Business and Management, 7 (14), 2018.

[10] J. Watuleke. E-procurement: evolution and adoption. a review of literature, IJRDO-Journal of Educational Research, 2456-2947, 2017.

[11] E. S. Kassim, \& H. Hussin. "A success model for the Malaysian Government e-procurement system: the buyer perspective" International Journal of Electronic Government Research (IJEGR), vol.9,1, 2013

[12] K. O. Ombat. Relationship between e-procurement systems and performance of procurement function in commercial banks in Kenya. International Journal of Economics, Commerce and Management, United Kingdom, 3 (12), 2015.

[13] J. J. Masele. “Adoption of green e-business applications for sustainable tourism development in developing countries the case of Tanzania" ( $\mathrm{PhD}$ Thesis), Department of Business Informatics I, VLBA-University of Oldenburg, 2014.

[14] T. Oliveira, \& M. F. Martins. Literature review of information technology adoption models at firm level, The Electronic Journal Information Systems Evaluation, 14 (1). Retrieved from www.ejise.com, 2011.

[15] United Republic of Tanzania National Information and Communications Technology Policy, Government Printers, Dar es Salaam, 2016.

[16] United Republic of Tanzania Public Procurement Regulatory Authority, Annual performance evaluation report for 2018/2019 financial year, 2019.

[17] United Republic of Tanzania Public Procurement Regulatory Authority, Annual performance evaluation report for 2017/2018 financial year, 2018.

[18] A. Kiwanuka. Acceptance process: the missing link between UTAUT and Diffusion of Innovation Theory. American Journal of Information Systems, 3, (2), 40-44, doi: 10.12691/ajis-3-2-3. 2015

[19] V. Venkatesh, M. G., Morris, G. B. Davis, \& F. D. Davis. "User acceptance of information technology: Toward a Unified View", MIS Quarterly, vol. 27, 3, pp. 425-478, 2003

[20] D. N. Shatta, F. A. Shayo, \& J. N. Layaa. Influence and linkage of buyers'suppliers' attitude towards e-procurement adoption in developing countries: Tanzania context. International Journal of Applied Research in Management and Economics, https://doi.org/10.33422/ijarme.v3i1.282, 2020b. 
[21] L. S. Chen, C. J., L. Y., Kuan, \& H. Huang Applicability of the UTAUT model in playing online game through mobile phones: moderating effects of user experience, IEEE Int'l Technology Management Conference, 2011.

[22] Y. K. Dwivedi, N. P., Rana, A., Jeyaraj, M., Clement, \& M. D. Williams Reexamining the Unified Theory of Acceptance and Use of Technology (UTAUT): towards a revised theoretical model, DOI, o10.1007/s10796-017-9774-y., 2017.

[23] L. Tornatzky, \& M. Fleischer, The Process of Technology Innovation, Lexington, MA, Lexington Books, 1990.

[24] M. Aboelmaged. The drivers of sustainable manufacturing practices in Egyptian SMEs and their impact on competitive capabilities: A PLS-SEM model. Journal of Cleaner Production, 175, 207-221, doi: ohttps://doi.org/10.1016/j.jclepro.2017.12.053, 2018.

[25] T. T. Hue. The determinants of innovation in Vietnamese manufacturing firms: an empirical analysis using a technology-organization-environment framework. Eurasian Business Review, 9(3), 247-267, doi:10.1007/s40821-019-00125-w., 2019.

[26] S. M. Chege, \& D. Wang. The influence of technology innovation on SME performance through environmental sustainability practices in Kenya. Journal of Technology in Society, 60, 101210, doi: https://doi.org/10.1016/j.techsoc.2019.101210, 2020.

[27] Y. Zhang, J. Sun, Z. Yang, \& Y. Wang. Critical success factors of green innovation: Technology, organization and environment readiness. Journal of Cleaner Production, doi: https:// doi.org/10.1016/j.jclepro.2020.121701., 2020.

[28] D. N. Shatta, F. A. Shayo, \& J. N. Layaa. Determinants of e-procurement adoption model for green procurement in developing countries: experience from Tanzania. International Academic Journal of Procurement and Supply Chain Management, 3(2), 1-18. $\quad$ Retrieved from http://www.iajournals.org/articles/iajpscm_v3_i2_1_18.pdf., 2020a.
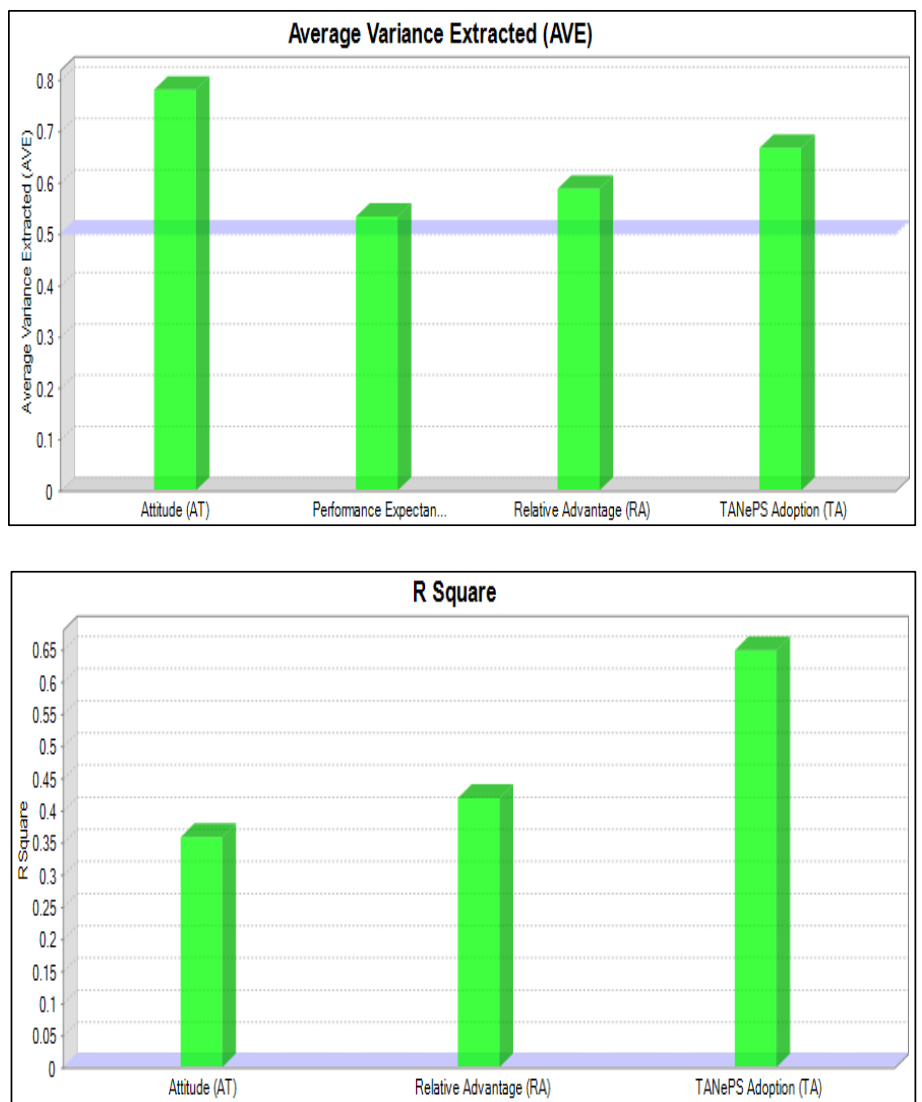

[29] B. Hwang, C. Huang, \& C. Wu. A TOE approach to establish a green supply chain adoption decision model in the semiconductor industry, Journal of Sustainability, doi:10.3390/su8020168., 2016.

[30] E. M. Rogers. Diffusion of Innovations (5th ed.). Free Press, New York, 2003.

[31] M. Suleiman. Adoption of e-procurement and value addition: Tanzanian context. European Journal of Business and Management, 7(14), 2015.

[32] J. F. Hair, C. M. Ringle, \& M. Sarstedt. "PLS-SEM: Indeed, a silver bullet" The Journal of Marketing Theory and Practice, vol.19, 2, pp. 139-152, 2014.

[33] J.F. Hair, J.J., Risher, M. Sarstedt, \& C.M. Ringle, (2018). "When to use and how to report the results of PLS-SEM" European Business Review, Permanent link to this document: available at: https://doi.org/10.1108/EBR-11-2018-0203 (May, 20,2020).

\section{APPENDIX A: KEY FINDINGS}

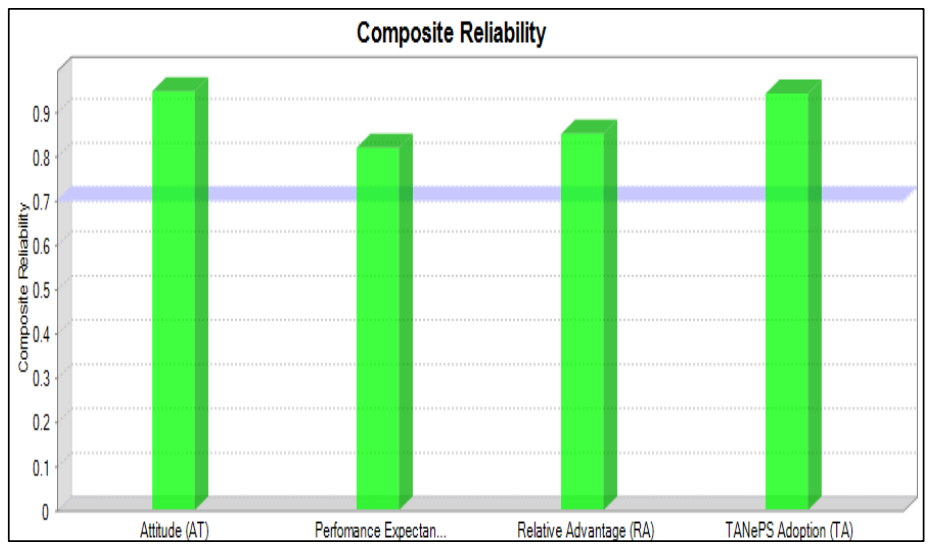

